\title{
O COMPORTAMENTO DO CONSUMIDOR QUE ATUA NO COMÉRCIO ELETRÔNICO E SEUS REFLEXOS NA ECONOMIA
}

Maria Aparecida da Silva Gomes ${ }^{1}$, Norma Lúcia da Silva², André Vasconcelos da Silva ${ }^{3}$, Adriana dos Santos Prado Sadoyama ${ }^{4}$

\section{RESUMO}

O comércio eletrônico ou e-commerce é o ambiente virtual onde as pessoas, sejam físicas ou jurídicas, acessam sites para realizar algum tipo de transação comercial, ou seja, vender, comprar, negociar, pagar dívidas, desde que seja utilizado qualquer meio eletrônico. Essa modalidade comercial surgiu com a invenção da internet nos períodos áureos da Guerra Fria, na década de 1960. Portanto, o objetivo geral deste artigo consiste em ressaltar o comportamento do consumidor que utiliza a tecnologia digital para suas negociações, bem como, seus reflexos na economia contemporânea. Para o alcance desse objetivo foi realizado um estudo bibliográfico e uma pesquisa de ordem qualitativa, com base em pesquisas experimentais. Por fim, foi possível ressaltar que o comportamento do consumidor que realiza suas transações comerciais no mercado eletrônico e seus reflexos na economia impacta diretamente a economia. À medida que o consumidor se interage com as empresas, passando a conhecer novos produtos/serviços, ele se torna mais exigente, questionador e participativo. Suas opiniões e decisões são influenciadas nas estratégias empresariais, o que reflete de forma positiva na economia nacional. Assim, conhecer o comportamento do consumidor digital é de suma importância para os empresários, economistas e demais envolvidos no processo econômico. É deste novo consumidor que dependerá o futuro de todas as nações. A era digital vem crescendo em todos os países e com perspectivas muito acima da média esperada pelas nações.

Palavras chave: Comportamento. Consumidor. Tecnologia digital.

\section{INTRODUÇÃO}

O mundo empresarial atravessa períodos de mudanças, devido o surgimento da internet que traz em seu contexto novas tecnologias, permitindo empresas e consumidores se interagirem de uma forma mais coerente, a fim de que ambos se sintam satisfeitos em suas negociações. Essa nova modalidade de negociação amplia o ambiente empresarial e representa um canal de vendas que as empresas começaram a usar para distribuir, vender, negociar e prestar serviços.

Com o avanço da tecnologia digital é comum que o consumidor torne-se mais

\footnotetext{
${ }^{1}$ Mestre em Gestão Organizacional - Regional Catalão - Universidade Federal de Goias/UFG.

${ }^{2}$ Mestre em Gestão Organizacional - Regional Catalão - Universidade Federal de Goias/UFG. ${ }^{3}$ Doutor em Ciências do Comportamento; Coordenador do Laboratório de Análise Organizacional e Consumo da
Universidade Federal de Goiás.

${ }^{4}$ Adriana dos Santos Prado Sadoyama. Professora da Universidade Federal de Goiás- Regional de Catalão. Professora do Mestrado profissional em Gestão Organizacional.
} 
exigente, pois o espaço para realização de suas compras não se resume em um layout de uma empresa. As barreiras geográficas foram substituídas por sites que são disponíveis aos consumidores para realização de pesquisas, comparação de preços, marcas, condições de pagamento, prazo para entrega do produto. Além de todos esses requisitos, o comportamento do consumidor que acessa a loja virtual para realizar suas compras e satisfazer suas necessidades precisa ser analisado, uma vez que alterando o seu processo de compra, suas atitudes em relação ao comércio eletrônico tende a afetar, de maneira positiva ou negativa, a economia tradicional.

Assim sendo, conhecer o comportamento do consumidor digital é de suma importância para os empresários, economistas e demais envolvidos no processo econômico. É deste novo consumidor que dependerá o futuro de todas as nações. A era digital vem crescendo em todos os países e com perspectivas muito acima da média esperada pelas nações.

Nesse contexto, surge o seguinte questionamento: Quais as mudanças que a tecnologia digital proporciona no comportamento do consumidor? Quais são os impactos das compras on-line na economia?

Como hipóteses destacam-se: a) nesse novo cenário impactado pela internet, o consumidor busca não somente atender suas necessidades, mas satisfazer seus desejos culturais, sociais, psicológicos e humanos; b) os impactos gerados pelas compras on-line são a liberdade de comparação de preços, marcas e condições de pagamento; melhoria na lucratividade das empresas; realização de novas negociações e melhoria do posicionamento econômico no mercado internacional.

Portanto, o objetivo geral deste artigo consiste em ressaltar o comportamento do consumidor que utiliza a tecnologia digital para suas negociações, bem como, seus reflexos na economia contemporânea. Os objetivos específicos são: descrever o mundo digital e seus reflexos na economia; identificar o perfil do consumidor digital; apontar os fatores psicológicos que influenciam a reação dos consumidores ao realizar compras on-line.

Para o alcance desses objetivos segue-se um embasamento teórico, abordando o parecer de diversos autores sobre mercado digital, comportamento do consumidor e economia digital. Foram selecionados artigos que relatam estes assuntos e, após uma leitura apreciativa de seus conteúdos, a elaboração do conteúdo abordado nestas páginas. O trabalho divide-se da seguinte maneira: no primeiro tópico encontra-se a Introdução; no segundo, o embasamento teórico, que se divide em quatro subitens: e-commerce; comportamento do consumidor digital; seus impactos na economia tradicional. Por fim, seguem-se as considerações finais.

\section{EMBASAMENTO TEÓRICO}

\subsection{Contextualização do e-commerce no mundo empresarial}

O comércio eletrônico ou e-commerce é o ambiente virtual onde as pessoas, sejam físicas ou jurídicas, acessam sites para realizar algum tipo de transação comercial, ou seja, vender, comprar, negociar, pagar dívidas, desde que seja utilizado qualquer meio eletrônico. Essa modalidade comercial surgiu com a invenção da internet nos períodos áureos da

guerra Fria, na década de 1960 (ESCOBAR e CAMARGO, 2012). Na visão desses autores, a internet surgiu com o propósito de superar dois grandes blocos ideológicos: Estados Unidos e União Soviética. Como ferramenta inovadora, a internet apareceu como sendo "um sistema desenhado para um fim específico e para um grupo homogêneo e restrito de usuários como meio de comunicação e troca de informações entre entidades de defesa militar e organizações científicas de um projeto de pesquisa militar." (ANDRADE et al, 2013, p. 01)

Certamente, na década de 1970 com a ampliação do uso dos programas em rede, o endereço eletrônico ou e-mail conquistou novos usuários, tornando-se o recurso mais acessível aos pesquisadores. No ambiente universitário foram criadas redes sociais como canal para favorecer a troca de informações e comunicação entre estudantes universitários. 
O facebook foi criado por universitários, com a finalidade de ampliar seus canais de diálogo para pesquisas e estudos. Mas a ambição e o comportamento do ser humano pela conquista de algo que ainda não existe, fez com que a internet conquistasse novos ambientes, sendo um deles o ambiente empresarial.

Assim, Andrade et al (2013) apontam que na década de 1980 surgem as primeiras aplicações comerciais no mercado digital. Os provedores de serviços da internet possibilitaram ao usuário comum 0 acesso à rede mundial de computadores sem se ausentar de sua casa. Tornou-se recurso de grande utilidade para as famílias, o que aumentou consideravelmente 0 número de servidores conectados à internet. As informações, antes inacessíveis, tornaram-se de fácil acesso às famílias ao redor do mundo.

Com a existência de um computador em sua residência e sua conexão com um provedor de internet, o ser humano e capaz de conhecer pessoas, trocar informações, se divertir, adquirir conhecimentos, transmitir informações e conteúdos a outras pessoas em qualquer lugar do planeta terra. Assim, a internet permite a efetivação de um grande número de transações, principalmente quando se compara ao comércio eletrônico. No ambiente comercial, a internet contribui para o aumento do volume de vendas, superando até mesmo a mioria das lojas físicas.

A facilidade de troca de informações via on-line foi um dos fatores que levou a internet a conquistar o comércio. Esse canal de vendas não somente leva informações ao usuário, mas também capta, atrai e prende a sua atenção. Por ser o modelo de negociação que mais cresce no mercado, os empresários procuram alguma forma de investir neste comércio visando o aumento de suas receitas, através das vendas on-line (ANDRADE et al, 2013).

O novo modelo de comércio prospera em larga escala graças à inteligência coletiva, formada por grupos de pessoas e empresas que coordenam suas estratégias. Alvarenga e Massarolo (2010) apontam que esses grupos de pessoas são formados por especialistas que fazem uso das suas habilidades, inteligência e conhecimento para criar algo novo ou modificar o que já existe, avisando atrair ainda mais a atenção dos consumidores.

Nesse contexto marcado pela globalização, a distribuição e democratização faz com que, economicamente, mais bens possam ser ofertados a um número maior de pessoas, devido a redução de custos e de preços. Além desses fatores, a cultura e a economia contemporânea favorecem a criação de grandes nichos de mercado, reduzindo dessa forma as vendas em locais físicos. Com base na teoria econômica, o comércio eletrônico modifica alguns pressupostos e se transforma na maior invenção desde que se criou a roda, pois vem modificando o mundo radicalmente, restando aos pesquisadores, empresários, economistas e interessados em estudar assuntos econômicos, apenas os manuais da velha economia (LOBLER, MADRUGA, PEDROZO, 2001).

Mais que em qualquer outro período histórico, o consumidor encontra à sua disposição, diferentes maneiras de adquirir um produto ou serviço, graças ao uso da tecnologia digital, aos avanços da informática e à difusão da internet, alcançando todos os países. Embora a função social da internet não seja apenas como canal de troca de informações, no comércio eletrônico sua finalidade se direciona ao consumo, compra e venda de produtos, às negociações. Por se tratar de um vasto campo de informações, o comércio eletrônico "é uma moderna forma de fazer negócios a fim de atender as necessidades de vendedores e compradores [...]" (MATEUS, JUNIOR e PINTO, 2013, p. 14). É válido lembrar que nesse comércio, são os próprios consumidores que realizam suas compras, apontam sugestões de mudança para os produtos, marcas ou serviços. Existe uma dupla relação envolvendo quem vende e quem compra.

Certamente, a diversidade de produtos e opções de contratação de serviços visam atender ao maior número possível de consumidores. Esse processo de troca entre empresas e consumidores, favorece o ganha-ganha, ou seja, ganha as empresas vendendo seus produtos e prestando serviços; ganha os consumidores adquirindo o que deseja para atender suas necessidades e ansiedades, gerando praticidade e economia.

Ao abordar o comércio eletrônico e seus impactos na economia, Costa (2009, p. 13) ressalta que "a velocidade com que a tecnologia digital evolui no mundo atual impõe às 
economias uma nova realidade na qual a plataforma tecnológica serve de base para novas maneiras de se distribuir conhecimento e para novas práticas de negócios entre empresas e seus clientes." Até o final do século XX o consumidor realizava suas compras no tradicional mercado de varejo. Ele selecionava o seu local de compra, descrevia o produto ao vendedor, analisava o preço, as condições de pagamento e concluía o negócio. A venda porta a porta ou realizada através de catálogos ou formulários perde sua importância.

Assim sendo, à medida que mais pessoas se conectam à internet para realização de negócios financeiros, comerciais, educacionais, culturais, religiosos, esportivos, novas ferramentas são criadas e disponibilizadas aos seus usuários. Nesse contexto de competitividade, o comércio eletrônico consolida o crescimento da economia nacional e gera incentivos para os empresários investirem nessa modalidade comercial. Surge assim a necessidade de conhecer o perfil e o comportamento do consumidor que faz uso da internet para realizar suas compras. Também, identificar os estímulos que o motivam a utilizar o comércio eletrônico para adquirir produtos que satisfaçam suas necessidades. O conteúdo a seguir aborda o comportamento e os estímulos que levam o consumidor a comprar através do uso da tecnologia digital.

\subsection{O perfil e os hábitos do consumidor que realiza suas compras no comércio eletrônico}

O perfil e as características do consumidor digital não se igualam ao do consumidor tradicional. Sendo o mundo digital complexo, sensível e perceptual, esse consumidor se sente mais envolvido e concentrado naquilo que aprecia através dos sites apresentados pelas empresas virtuais. Segundo Araujo e Crivelaro (2010), quando o individuo navega na internet para buscar informações sobre produtos ou serviços que deseja adquirir, sua percepção sensorial fica mais aguçada, por se encontrar mais envolvido e concentrado naquilo que está fazendo.

Os fatores psicológicos influenciam na decisão do consumidor quanto à concretização da compra on-line. Segundo Escobar e Camargo (2012), a motivação, a memória, a aprendizagem e a percepção estimulam a reação dos consumidores. Assim, ao elegerem o comércio eletrônico como opção de compra, o consumidor busca benefícios que satisfaçam suas necessidades. A praticidade, a rapidez na entrega do produto a segurança são os principais fatores que motivam as pessoas a realizar compras no comércio eletrônico.

Dessa forma, consumidores que não possuem experiências com o mundo digital podem encontrar dificuldades para efetuar suas compras. Uma vez que as compras on-line são realizadas sem contatos interpessoais diretos, sem a presença do vendedor, 0 consumidor digital tem a liberdade para consultar preços e comparar marcas, condições de pagamento, o que torna a compra on-line mais criativa.

Assim sendo, ao realizar suas compras on-line, o consumidor desempenha seis papéis diferenciados. De acordo com Las Casas (2006), esses papéis são: (i) Iniciador: é o individuo que propõe uma sugestão ou reconhece uma necessidade a ser superada através da aquisição de algum produto; (ii) Vigia: é o indivíduo que realiza a busca pelas informações no mercado digital, acompanha e controla o fluxo de informações disponíveis; (iii) Influenciado: é o indivíduo que incentiva a realização da compra; (iv) Decisor: é o indivíduo que decide o que comprar; (v) Comprador: é o indivíduo que concretiza a compra; (vi) Usuário: é o indivíduo que utiliza o produto ou serviço. Em cada fase, o comportamento é alterado e sofre impactos do meio social, cultural, econômico, político, no qual o indivíduo vive.

O comportamento do consumidor sofre alterações conforme suas necessidades. Essas mudanças ocorrem ao passar dos anos e, em cada geração, as atitudes, os hábitos e o perfil são modificados de acordo com os reflexos do meio social onde vive. De acordo com Sheth et al (1998), os primeiros estudos sobre comportamento do consumidor surgiram no início da década de 1950. Esses estudos eram sustentados por três aspectos distintos: "(i) o comportamento do consumidor é um subsistema de comportamento; (ii) o consumo 
preponderante dos produtos tangíveis e de bens duráveis; (iii) o entendimento do comportamento em oposição a outros tipos de opções, como classe de produto, volume ou momento de escolha."(SHETH et al, 1988,p. 109). Ao comentar sobre o que as pessoas consomem, como e por que tais produtos são consumidos, o que se evidencia é o comportamento desses indivíduos aos realizar essas ações. Estudar esse comportamento abrange áreas do conhecimento como psicologia, economia, antropologia, sociologia, comunicação.

Nesse sentido, todas as atividades desenvolvidas por pessoas com a finalidade de compra, consumo, descarte ou qualquer transação que envolva o papel do comprador, pagador ou usuário, chamam a atenção dos estudiosos do comportamento do consumidor. Uma pessoa o papel de comprador quando realiza buscas e compras de produtos e serviços, valorizando a conveniência e a personalização do atendimento. Quando a pessoa se responsabiliza pelo pagamento da compra e age de acordo com os aspectos financeiros (preço, crédito, débito), diz-se que ela assume o papel de pagador. O usuário é aquele que faz uso do produto ou desfruta do serviço adquirido no processo de compra, levando em consideração suas necessidades, hábitos e desejos.

Assim, conhecer o perfil e os hábitos do consumidor que realiza suas compras no mundo digital é considerado moderno, uma vez que essa opção de fazer compras surgiu recentemente, ou seja, a partir da década de 1990. Como principais características, esse consumidor é considerado, pelas empresas, como exigente, sugestivo e incentivador. São os sue pensamentos, sentimentos, ações, desejos e necessidades que determinam as mudanças no mercado empresarial. Além de realizar suas compras pela internet, esse consumidor é capaz de propor mudanças nos produtos e serviços ofertados pelas empresas em seus sites.

Para entender o processo de compra realizado pelo consumidor no mercado digital é necessário a existência de dois fatores: necessidade e desejo. Por necessidade, Souza e Pinheiro (2014) consideram um estado de privação, carência ou sensação de algo que seja essencial para um indivíduo. $O$ desejo se refere a um estado psicológico direcionado à obtenção de algo para si mesmo, sem que exista uma carência, que justifique as ações e sentimentos decorrentes. Esses dois fatores despertam no individuo o interesse pela compra de produtos/serviços que são disponibilizados no comércio eletrônico, a fim de satisfazer suas necessidades.

$\mathrm{Na}$ visão de Mateus, Alencar Jr. e Pinto (2013, p. 15), o comportamento do consumidor que faz suas compras on-line, "pode ser compreendido e explicado pelos mesmos parâmetros de tipologias e fatores que influenciam no processo de decisão de compra dos consumidores de lojas físicas (reais)." De acordo com esses autores, os consumidores on-line não podem ser vistos como um nicho de mercado, formado por um grupo de pessoas com os mesmos desejos e necessidades. Portanto, é importante a compreensão e atenção por parte das empresas ao expor seus produtos e/ou serviços neste mercado, os quais podem ser apreciados por pessoas de qualquer grupo social, gênero, cultura, idade, religião, estado ou nação.

Nesse cenário, compreender o comportamento do consumidor que realiza suas compras no mercado digital é uma tarefa complexa. Essa complexidade se explica devido ao fato de que o comportamento de compra e consumo é afetado por fatores que variam de acordo com cada indivíduo. Esses fatores são: interesses pessoais, envolvimento, motivação, atitudes, conhecimentos, valores, personalidade, estilo de vida, classe social, família, cultura, situação, influências pessoais e processos psicológicos.

Os grupos sociais, como os amigos e famílias, conhecidos como "grupos de afinidades" influenciam nas decisões do indivíduo ao realizar suas compras on-line. Essa influência se presencia de três formas, conforma aponta Costa (2009): (i) informacional, quando se busca informações sobre determinados produtos, marcas e serviços junto a especialistas ou pessoas que conhecem o produto pretendido ou outro semelhante; (ii) utilitária, quando a aquisição de um produto visa satisfazer as expectativas e necessidades de familiares ou colegas de trabalho; (iii) expressiva de valor, quando a compra de um produto gera a melhoria do status social de quem o comprou. 
Assim, chama a atenção os motivos que levam uma pessoa a se tornar um consumidor. Esses motivos foram organizados por Engel, Blacwell e Miniard (2009), em dois grupos: pessoais (busca de novas tendências, diversão, papel desempenhado perante a sociedade, estimulação sensorial, autogratificação e atividade física) e sociais (convivência com outras pessoas, incentivo de grupos de pessoas do mesmo nível, prazer de comprar, diálogo com outras pessoas que apresentam interesses similares).

Com o uso da internet para realização de suas compras, Costa (2009) propõe uma revisão nas teorias de comportamento do consumidor. Embora a compra ocorra no ambiente virtual, as atitudes, os gostos, desejos e apreciação por um determinado produto fazem parte de seu processo decisório. Este consumidor pode apresentar insegurança, pessimismo, insatisfação, otimismo, satisfação, desejo, ou qualquer atitude diferenciada ao imaginar a concretização de seu processo de compra.

Se o consumidor nunca comprou no mercado eletrônico, ao realizar sua primeira compra pode apresentar insegurança, medo, pessimismo. Geralmente, a primeira compra on-line é feita em sites de empresas famosas no mundo on-line. Esses sentimentos vão desaparecendo à medida que as compras são realizadas no mundo off-line. Diante dessas circunstâncias, verifica-se que o consumidor digital conquista cada vez maior espaço no comércio eletrônico. Suas atitudes, disponibilidades para pesquisas de preços, produtos, marcas, condições de pagamento, prazo de entrega, facilidade de busca e comparação são fatores que precisam ser observados pelos profissionais de vendas.

Segundo Bosio (2013), nesse cenário marcado pela tecnologia digital, o perfil do consumidor, seus desejos e necessidades ganharam importância entre os economistas, profissionais de vendas, psicólogos, sociólogos e demais pesquisadores sociais. Esse perfil mudou muito e continua mudando, de acordo com as alterações que ocorrem no ambiente social, econômico, político, cultural, educacional.

Assim sendo, para atuar no comércio eletrônico qualquer empresa precisa estar conectada às redes sociais e ter capacidade para operá-las adequadamente. Também, conhecer o perfil desse consumidor, o qual se torna cada vez mais exigente, apreciador, crítico e flexível. Os reflexos na economia são visíveis, pois à medida que as empresas vendem seus produtos, as mesmas renovam seus estoques e lançam produtos novos no mercado.

\subsection{Os impactos do consumidor digital na economia contemporânea}

Com o fácil acesso às informações, o consumidor passou a ter maior poder sobre suas decisões de consumo, o que significa que suas ações influenciam, direta e indiretamente, na economia. A realidade é que a internet propõe um novo modelo de gerar negócios, seja entre empresas ou entre empresas e consumidor. (LOBLER, MADRUGADA, PEDROZO, 2001).

Nesse cenário surge uma nova economia que envolve empresas ".com", as quais aguardam seus lucros e integram um futuro não muito distante. As empresas que pertencem à economia tradicional continuam com os mesmos processos de vendas e retenção de lucros. Uma grande revolução econômica, marcada pela tecnologia digital, já iniciou com a invenção da internet.

Alvarenga e Massarolo (2010) ressaltam que a cultura e a economia da sociedade contemporânea se avançarão cada vez mais para um modelo de negócio sem fronteiras, baseado na relação da oferta e da demanda digitais. $O$ consumidor não é mais aquele passivo, mas passa a atuar como porta voz do produto, participa ativamente nas decisões, seja para realizar novas demandas ou para defender seus interesses.

Economicamente, mais produtos são ofertados para uma demanda maior, devido a facilidade de acesso aos canais digitais e mais informações sobre os produtos ofertados. $\mathrm{Na}$ economia digital uma empresa torna-se mais lucrativa na medida que investe em programas, sites e redes sociais para exposição de seus produtos/serviços no mercado virtual.

Graças ao poder da inteligência coletiva, esse modelo econômico prospera em larga 
escala. Novos nichos de mercado são formados por especialistas amadores que empregam suas habilidades para formação de uma base de relacionamento com mercadorias diferenciadas, a fim de demonstrar seu domínio sobre a cultura popular. Esse mundo gerado e controlado pelo consumidor digital consegue moldar os hábitos dos demais consumidores, o que ocorre através de prazeres proporcionados por uma única ferramenta digital, seja ela a televisão, computador, internet, celular, ou qualquer outra.

Segundo Alvarenga e Massarolo (2010), o consumidor ávido e devotado, que na sociedade industrial era reconhecido como consumidor passivo, tornou-se o detentor do "capital social" e um dos principais agentes de mercado. Seu talento e sua competência não eram valorizados pelas indústrias e muito menos pelas academias. A tendência é que este perfil de consumidor torne-se cada vez mais atuante na economia digital.

Por serem pessoas interativas, ativas e participativas, esses consumidores compartilham interesses e, mesmo que se encontrem geograficamente distantes, identificam o mesmo objeto, formam nichos de mercado e decidem sobre o que comprar. O que se presencia é uma mudança na relação entre produtor e consumidor, que na economia tradicional era basicamente definida: a indústria produz o produto e o consumidor final aprecia-o.

Para entender essa mudança causada na economia, Alvarenga e Massarolo (2010) apontam a visualização do novo modelo econômico que invade o mercado. O capital social é resultado das interações entre empresas e consumidores (B2C) e consumidores $X$ consumidores ( $\mathrm{C} 2 \mathrm{C}$ ); envolve um conjunto de habilidades, conhecimentos e atribuições que permitem aos indivíduos influenciar nas opiniões de outros sobre marcas, preços, produtos e serviços.

Assim, a internet está revolucionando o comércio. Seu rápido crescimento no mercado permite o acesso de pessoas físicas, a qualquer momento e sem limites de espaço, a uma diversidade de produtos e de estabelecimentos virtuais, para realização de suas compras. O consumidor torna-se o principal agente que revoluciona o cenário econômico. O seu comportamento sofre alterações conforme as mudanças que ocorrem no mundo digital.

\subsection{Resultados de pesquisas experimentais envolvendo o estudo do comportamento do consumidor digital}

O conteúdo a seguir aponta resultados obtidos com pesquisas experimentais, direcionadas ao estudo do comportamento do consumidor. Portanto, foram selecionados cinco artigos direcionados a este assunto.

a) Em seu estudo que traz por título "A indústria audiovisual e os novos arranjos da Economia Digital", os autores Alvarenga e Massarolo (2010) desenvolveram algumas reflexões sobre as mudanças que estão ocorrendo na gestão produtiva e seus impactos na indústria audiovisual. Os autores consideram que o uso da tecnologia digital visa uma melhor relação entre empresa e consumidor, o que é de suma importância para a prevalência da economia digital. Essa participação direta dos consumidores na escolha, compra e produção de mercadorias, que são expostas no mercado digital, não visa destruir a economia tradicional, mas enriquecê-la através de resultados de pesquisas realizadas envolvendo consumidores de todas as esferas sociais, gêneros, países, níveis educacionais e culturas. A tendência do consumidor digital é preferir produtos para os quais é convidado a participar de seu processo produtivo, relegando produtos que já se encontram prontos para compra.

b) Em seu artigo que traz por título "O comércio eletrônico e o comportamento de compra dos consumidores finais", os autores Andrade et al (2013) realizaram um estudo exploratório e uma pesquisa de campo, por meio de entrevistas com 323 pessoas, constituindo uma amostra que integra a Região Metropolitana de Belo Horizonte, que acessa a internet para realizar suas compras. Essas pessoas possuem idade acima de 15 anos, sendo a maior parte do sexo masculino e que possui nível de escolaridade Ensino Médio completo ou incompleto $(63,4 \%)$. Quanto à renda familiar, o maior índice encontrado está entre as 
pessoas que ganham de quatro a sete salários mínimos (30,4\%). Ficou comprovado que a maioria absoluta $(94,8 \%)$ domina ou possui conhecimento básico de informática. Os autores concluíram que o comércio eletrônico tende a dominar os processos de compra e venda, melhorando a economia nacional, através do lucro gerado para as empresas que investem nesta área. Os autores ressaltam que, no início do surgimento do comércio eletrônico, a comercialização baseava-se exclusivamente em livros e produtos eletrônicos. Com a expansão do e-commerce, as empresas aumentaram consideravelmente o lançamento de novos produtos em seus portais de acesso. Os autores concluem que o comportamento do consumidor não sofreu profundas alterações quando se compara com pesquisas anteriores, porém, o preço e a comodidade continuam sendo os principais fatores que motivam a realização de compras on-line. É fundamental que as empresas ofereçam segurança aos consumidores quanto ao uso da tecnologia digital para aquisição de seus produtos e/ou serviços.

c) Em seu artigo "A realidade e as promessas do comércio eletrônico: entendendo o consumidor final", os autores Lobler, Madruga e Pedrozo (2001) realizaram uma pesquisa envolvendo servidores da Universidade Federal de Santa Maria (UFSM), incluindo técnicos administrativos e docentes. Essa amostra possui faixa etária entre 41 a 50 anos, sendo que a grande maioria (39\%) concluiu um curso superior e $51 \%$ são pessoas do sexo masculino. Por envolver um ambiente acadêmico, esta pesquisa chegou à conclusão de que os produtos mais requisitados em suas compras on-line são livros e eletrônicos; os menos solicitados são aqueles que precisam ser vistos e apreciados fisicamente, antes de adquirir (automóveis, roupas e flores). Os autores concluíram que o índice de clientes satisfeitos com suas compras on-line é alto, porém a insatisfação dos consumidores chama a atenção dos pesquisadores, principalmente quando as empresas não cumprem as promessas expostas em seus sites eletrônicos. A falta de um atendimento personalizado e a ausência da credibilidade direcionada à qualidade do produto, são fatores que merecem mais atenção por parte das empresas que realizam vendas on-line.

d) Em seu artigo "E-commerce: um estudo sobre o comportamento dos consumidores na Nerdstore", os autores Souza e Pinheiro (2014) realizaram uma pesquisa descritiva transversal e simples, através da aplicação de um questionário estruturado com perguntas claras e objetivas e disponibilizado em vários canais sociais, através do Google Docs. Foi obtida uma amostra de 330 respostas ao questionário aplicado. Com a coleta e tabulação de dados, os autores mostram que os consumidores que visitam o site jovem Nerd possuem perfil com características semelhantes. A maioria sempre faz compras pela internet, o que cresce significativamente o número de conexões via mobile. A confiança e a credibilidade fazem com que os internautas se sintam mais motivados a realizar suas compras nas lojas virtuais. A interação entre empresa e consumidor, os conteúdos disponíveis nos sites e a segmentação de mercado são fatores que influenciam a venda on-line.

e) Em seu artigo "As mudanças culturais nas organizações, na área contábil e no governo em função do SPED”, os autores SantÁna e Teló (2010) realizam uma pesquisa experimental envolvendo 16 pessoas, através da aplicação de um questionário, visando saber se a conversão de documentos de controle em papel por sua versão digital, através do Sistema Público de Escrituração Digital, criado pelo Governo Federal em janeiro de 2007, mediante o decreto 6022, gera mudanças e melhorias nos serviços contábeis. Os autores observaram que o novo sistema exige uma mudança cultural principalmente por parte dos profissionais contábeis, a fim de que os mesmos possam motivar os empresários a usar essa ferramenta digital. Mesmo sendo indispensável para o processo contábil, o SPED pode se tornar uma limitação para os seus usuários, uma vez que a utilização desse recurso digital gera custos, e muitas pequenas empresas correm o risco de serem excluídas do mundo digital. Foi possível evidenciar que as mudanças geradas pela implantação desse sistema digital pode causar resistência a algumas pessoas, devido a falta de instrução e conscientização da mudança de postura na adequação do uso da tecnologia digital.

\section{CONSIDERAÇÕES FINAIS}


O conteúdo abordado neste artigo ressaltou o comportamento do consumidor que realiza suas transações comerciais no mercado eletrônico e seus reflexos na economia. À medida que o consumidor se interage com as empresas, passando a conhecer novos produtos/serviços, ele se torna mais exigente, questionador e participativo. Suas opiniões e decisões são influenciadas nas estratégias empresariais, o que reflete de forma positiva na economia nacional. As empresas tornam-se mais competitivas e inovadoras, ao mesmo tempo que os consumidores buscam novidades e produtos de qualidade.

Uma vez que novos produtos são oferecidos, cresce a demanda e o consumo. Em plena era digital, a tendência é que o consumidor assuma uma postura diferenciada neste processo econômico. Seu comportamento, suas opiniões e análises de preços, marcas, pontos estratégicos de vendas, representam a base para a nova economia, que traz como foco cultural o uso da tecnologia digital.

Assim, sendo este artigo destacou que os hábitos e o perfil do consumidor passam por um processo de transição. De um simples comprador, torna-se um agente apreciador, crítico e flexível. Suas atitudes e decisões de compras influenciam a economia e os resultados já podem ser vistos, pois cresce o índice de compras on-line, tanto no mercado nacional quanto internacional.

Por ser um assunto de grande relevância para a sociedade, que se encontra em transição de uma fase manual para digital, surgem oportunidades para a realização de novas pesquisas abordando o comportamento do consumidor. 


\title{
CONSUMER BEHAVIOR IN ELECTRONIC COMMERCE AND ITS REFLECTIONS IN THE ECONOMY
}

\begin{abstract}
Electronic or e-commerce trade is the virtual environment where people, whether individuals or companies, visit sites to carry out some type of commercial transaction, that is, sell, buy, trade, pay debts, provided it is used any electronic medium. This business arrangement came up with the invention of the internet in the golden periods of the Cold War, in the 1960. Therefore, the objective of this article is to highlight the behavior of consumers using digital technology to their negotiations, as well as its impact on the contemporary economy. To achieve this goal we conducted a bibliographic study and a qualitative research, based on experimental research. Finally, it was possible to point out that consumer behavior that conducts its business transactions in the electronic market and its impact on the economy directly impacts the economy. As the consumer interacts with business, getting to know new products / services, it becomes more demanding, questioning and participatory. Your opinions and decisions are influenced in business strategies, which reflects positively on the national economy. Therefore, knowing the digital consumer behavior is extremely important for entrepreneurs, economists and others involved in the economic process. This is the new consumer will depend on the future of all nations. The digital age is growing in all countries and with prospects well above the average expected by nations.
\end{abstract}

Keywords: Behavior. Consumer. Digital Technology.

\section{REFERÊNCIAS BIBLIOGRÁFICAS}

ALVARENGA, M. V. T. ; MASSAROLO, J. C. A Indústria Audiovisual e Os Novos Arranjos da Economia Digital. In: Alessandra Meleiro. (Org.). Indústria Cinematográfica e Audiovisual Brasileira. São Paulo: Escrituras Editora, 2010, v. 3, p. 119-134.

ANDRADE, M. L.. O Comércio Eletrônico e o Comportamento de Compra dos Consumidores Finais. Revista Eletrônica de Gestão (Administração e Ciências Contábeis), v. 10, p. 1-20, 2013.

ARAUJO, Marina Pinto de Oliveira; CRIVELARO, Marcos. Turismo virtual on line: Canal de decisão de compra para roteiros ecológicos no Brasil. 1 Simpósio Brasileiro de Ciência de Serviços. Brasília, 17-19/11/2010.

ARNOUD, Analu Neves Dias. Breve considerações sobre o contrato de consumo no comércio eletrônico internacional. Disponível em: https://jus.com.br/1031255-analu-nevesdias-arnoud/publicacoes. Acesso em 15 de Dez. 2015. 
BOSIO, Eric Losala. Uma análise exploratória do comércio eletrônico no varejo brasileiro nessa última década. Trabalho apresentado ao Departamento de Ciências Econômicas da Universidade Federal do Rio Grande do Sul. 2013.

COSTA, Fabiano Leite. Comércio eletrônico: Hábitos do consumidor na internet. Dissertação apresentada ao Mestrado Profissional em Administração das Faculdades Pedro Leopoldo. Pedro Leopoldo: Fipel, 2009.

ESCOBAR, Claudio; CAMARGO, Ricardo Araujo. E-commerce: B2W: O consumidor no mundo das vendas on-line/ o nível de qualidade do serviço e a frustração do consumidor. Anais do IV Seminário Eniac. 2012.

LAS CASAS, Alexandre Luzzi. Administração de marketing: Conceitos, planejamento e aplicações à realidade brasileira. São Paulo: Atlas, 2006.

LÖBLER, Mauri. L. ; MADRUGA, L. ; PEDROSO, S. P. A realidade e as promessas do comércio eletrônico: entendendo o consumidor final. In: ENCONTRO NACIONAL DE ENGENHARIA DE PRODUÇÃO, 2001, Salvador (BA). Anais do XXI Encontro Nacional de Engenharia de Produção, 2001. p. 1-8.

MATEUS, Karla Maria; ALENCAR JR, Rusdael; PINTO, Liliane Araújo. Comportamento do consumidor do comércio eletrônico: uma pesquisa com estudantes da UFPI-CSHNB. 2013.

RODRIGUES, Zaila M. O. de Castro; SOUZA, Cristiane Madeiro A. de; PESSOA, Rosângela Andrade; OLIVEIRA, Oderlene Vieira de; ARAÚJO, Francisca Camille Martins. O perfil do consumidor universitário de e-commerce de Fortaleza. XI Simpósio de Excelência em Gestão e Tecnologia. Gestão do Conhecimento para a sociedade, 22, 23 e 24 de outubro de 2014.

SANTÁNA, Marcos Aurélio da Silva; TOLÓ, Admir Roque. As mudanças culturais nas organizações, na área contábil e no governo em função do SPED. Programa de Apoio à Iniciação Científica. PAC 2009-2010.

SHETH, Jagdish N.; GARDNER, David M.; GARRET, Dennis E. Marketing Theory: evolution and evolution. New York: John Wiley \& Sons, 1988.

SOUZA, Carlos Amauri de; PINHEIRO, Marco Antônio. E-commerce: um estudo sobre o comportamento dos consumidores da Nerdstore. Trabalho apresentado XV Congresso de Ciências da Comunicação na Região Sul- Palhoça-SC; 08 a 10/05/2014. 